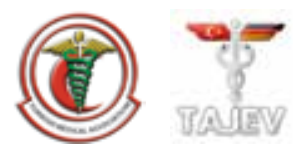

\title{
Effect of chorionic villus sampling on the occurrence of preeclampsia and gestational hypertension: An updated systematic review and meta-analysis
}

\author{
Ahmet Başaran', Mustafa Başaran¹, Betül Topatan², James N. Martin Jr. ${ }^{3}$ \\ ${ }^{I}$ Department of Obstetrics and Gynecology, Konya Training and Research Hospital, Konya, Turkey \\ ${ }^{2}$ Department of Anesthesiology, Konya Training and Research Hospital, Konya, Turkey \\ ${ }^{3}$ Department of Obstetrics and Gynecology, Division of Maternal-Fetal Medicine, University of Mississippi Medical \\ Center, Jackson, Mississippi, USA
}

\section{Abstract}

Objective: To perform a meta-analysis for an assessment of the risk of preeclampsia or gestational hypertension following chorionic villus sampling (CVS).

Data source: PubMed was systematically searched from its inception through January 2016.

Material and Methods: Nine reports were identified. A pre-specified scale was used to assess their quality.

Tabulation, integration, and results: We performed pooling into three subgroups with respect to the control group: A) Patients with no invasive prenatal diagnostic procedure served as a control group for comparison. The odds ratios for gestational hypertension (0.76, $95 \% \mathrm{CI}$ $0.46-1.26)$, preeclampsia $(0.83,95 \%$ CI $0.42-1.67)$, and severe preeclampsia (0.49, 95\% CI 0.04-5.78) or when hypertension categories were pooled $(0.80,95 \%$ CI $0.46-1.41)$ were not significantly different. B) Patients with midtrimester diagnostic amniocentesis and patients with no invasive prenatal diagnostic procedure were combined as a control group for comparison. The odds ratios for preeclampsia (1,95\% CI 0.46-2.18), severe preeclampsia $(0.83,95 \%$ CI $0.14-4.85)$, and pooled hypertension categories (1.07, 95\% CI 0.63-1.84) were not significantly different. C) Patients with midtrimester diagnostic amniocentesis served as a control group. There was a significant difference in the odds ratio for preeclampsia between the CVS and amniocentesis groups (2.47, 95\% CI 1.14-5.33). There was a marginal difference in the odds ratio for combined pregnancy-induced hypertension categories between the CVS and amniocentesis groups (1.61, 95\% CI 1.02-2.53).

Conclusion: The available data do not indicate an increased risk of preeclampsia or gestational hypertension following first trimester CVS. The heterogeneity and retrospective design of existing studies are limiting factors for our analysis and findings.

(J Turk Ger Gynecol Assoc 2016; 17: 65-72)

Keywords: Meta-analysis, chorionic villus sampling, preeclampsia, midtrimester diagnostic amniocentesis

Received: 8 February, 2016 Accepted: 22 March, 2016

\section{Introduction}

Preeclampsia affects $5 \%-8 \%$ of all pregnancies. Together with the other hypertensive disorders of pregnancy, including gestational hypertension, it is a major contributor to maternal and perinatal morbidity and mortality $(1,2)$. Although significant advances have been made in elucidating the etiopathogenesis of preeclampsia, the identification of the specific cause(s) of this syndromic disorder remains elusive; therefore, it continues to be classified as a syndrome and not a single disease entity (3).

Current knowledge about the pathogenesis of preeclampsia suggests that altered placental development and disturbances in the transformation of the spiral arteries in early pregnancy play critical roles in the progression of events that initiate a spectrum of pregnancy-induced hypertensive disorders $(4,5)$. The first trimester diagnostic procedure of chorionic villus sampling (CVS) has been shown to cause some degree of bleeding and disruption at the feto-maternal placental interface, which is demonstrated by elevated maternal levels of alphafetoprotein and pregnancy-associated plasma protein A $(6,7)$. This disruption in the developing placental-decidual interface secondary to CVS during early pregnancy has been postulated to potentially cause subsequent abnormal placental development. A possible consequence of CVS could be an increased occurrence of hypertensive complications of pregnancy (8). Here, we will review the recent literature and update our previous systematic review and meta-analysis (9) to investigate the potential role of CVS in increasing the subsequent rate of occurrence of preeclampsia and gestational hypertension. 


\section{Material and Methods}

The current meta-analysis conforms to the guidelines outlined by the Meta-analysis of Observational Studies in Epidemiology (MOOSE) and was performed in accordance with the indicated statement (10).

\section{Search strategy}

We searched PubMed from its inception through January 2016 to identify studies that evaluated CVS and the subsequent occurrence of preeclampsia or gestational hypertension (Figure 1). The search terms and queries that were used in the PubMed search are provided in Table 1 . We discovered additional studies by searching the bibliographies of the discovered studies, letters to editors, guidelines, and review articles and included these citations if they were found to be relevant to the subject matter being studies.

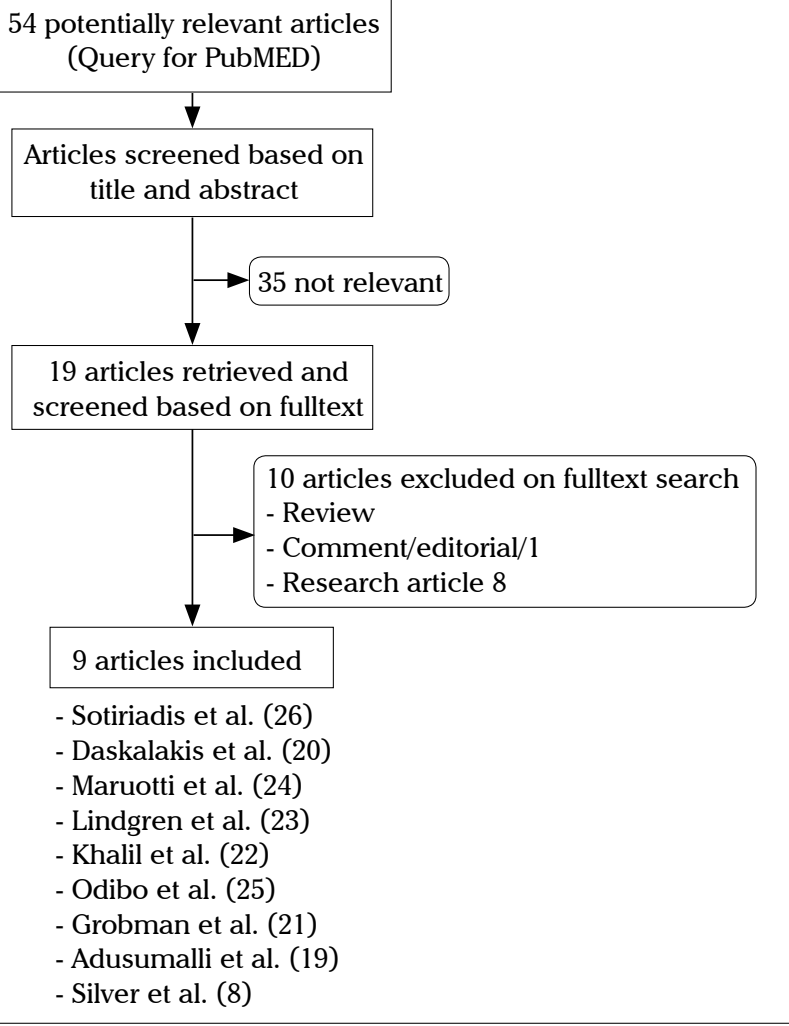

19 articles retrieved and screened based on fulltext

\begin{tabular}{l} 
Particles included \\
\hline $\begin{array}{l}10 \text { articles excluded on fulltext search } \\
- \text { Review } \\
- \text { - Remment/editorial/1 } \\
\text { - Research article } 8\end{array}$ \\
- Sotiriadis et al. (26) \\
- Daskalakis et al. (20) \\
- Maruotti et al. (24) \\
- Lindgren et al. (23) \\
- Khalil et al. (22) \\
- Odibo et al. (25) \\
- Grobman et al. (21) \\
- Adusumalli et al. (19) \\
- Silver et al. (8)
\end{tabular}

Figure 1. Search strategy

\section{Study selection}

The relevant studies were independently reviewed by two reviewers to grade them for quality and to determine their eligibility for inclusion in this systematic review and meta-analysis according to the following criteria:

a) Studies designed to compare CVS with a control group and/ or amniocentesis and/or

b) Studies that report odds ratios (ORs) or data for the occurrence of preeclampsia and/or gestational hypertension as acute-onset, non-chronic hypertensive complications of pregnancy; and

c) Studies in the English language.

\section{Assessment of reporting and study quality}

The two reviewers independently and separately evaluated the reporting and study quality of the included studies. The two reviewers undertook this task using a pre-specified assessment scale, which was developed for the evaluation of the methodology used in retrospective clinical studies (11). Discussions about the interpretation and scoring of the checklist were undertaken before the initiation of the assessment and data abstraction procedure. Several items of the indicated quality assessment checklist were irrelevant and were accordingly removed. The maximum overall score that was possible using the customized quality assessment checklist was 22 . To evaluate each individual study independently, associated spreadsheets were arranged for each reviewer for their assessment of the included studies.

\section{Data abstraction}

From the manuscripts that were determined to be appropriate for inclusion in the analysis, information regarding the year of the study, design of the study (retrospective versus prospective), sample size, nulliparity, maternal age, smoking status, body mass index, and hypertensive complications of pregnancy, which included gestational hypertension, preeclampsia, and severe preeclampsia, were extracted when available. Table 2 lists the characteristics of the studies and the extracted information. Two reviewers independently extracted the data, which were cross-checked by the authors (Table 3). We discussed any discrepancies between the two reviewers. Discrepancies were resolved by consensus among the authors.

Table 1. Search terms and query for PubMed search

Search terms

Query for PubMed
"Villus sampling," "chorionic villus sampling," "chorionic villi sampling," "chorionic villous sampling," "CVS," "invasive diagnostic procedure," "prenatal invasive," "hypertensive disorders," "preeclampsia," "pre-eclampsia," "pregnancy induced hypertension," "PIH," "eclampsia," "hypertension," "pregnancy," "proteinuria"

("Chorionic Villous Sampling"[TIAB] OR "Chorionic Villus Sampling"[TIAB] OR "CVS"[TIAB] OR "invasive diagnostic procedure"[TIAB] OR "Chorionic Villi Sampling"[MeSH Terms]) AND ("Hypertension, Pregnancy-Induced"[MeSH Terms] OR "Pre-eclampsia"[MeSH Terms] OR "preeclampsia" [TIAB] OR "Pregnancy induced hypertension" [TIAB] OR "PIH"[TIAB] OR "gestational hypertension" [TIAB] OR ("hypertensive disorder"[TIAB] AND "pregnancy"[TIAB]) OR ("hypertension"[TIAB] AND "pregnancy"[TIAB] AND "proteinuria"[TIAB]) OR ("hypertensive disorders"[TIAB] AND "pregnancy"[TIAB]) OR "eclampsia"[TIAB]) 
Table 2. Characteristics of the studies included in the meta-analysis

\begin{tabular}{|c|c|c|c|c|c|c|c|c|}
\hline Study/year & $\begin{array}{l}\text { Study } \\
\text { design }\end{array}$ & \begin{tabular}{|c|} 
Number of \\
participants \\
who underwent \\
amniocentesis
\end{tabular} & \begin{tabular}{|c|} 
Number of \\
participants \\
who underwent \\
CVS
\end{tabular} & \begin{tabular}{|c|} 
Number of \\
participants \\
with no invasive \\
procedure
\end{tabular} & $\begin{array}{c}\text { Maternal } \\
\text { age control/ } \\
\text { CVS groups }\end{array}$ & $\begin{array}{l}\text { Nulliparity } \\
\text { control/ } \\
\text { CVS groups }\end{array}$ & \begin{tabular}{|c|} 
Body mass \\
index \\
control/ \\
CVS groups
\end{tabular} & $\begin{array}{c}\text { Smoking } \\
\text { status } \\
\text { control/ } \\
\text { CVS groups }\end{array}$ \\
\hline Daskalakis et al. (20) & Retrospective & 6875 & 3243 & - & $30.0 / 35.5$ & $41.1 \% / 45.1 \%$ & $28.4 / 28.3$ & $6.5 \% / 6 \%$ \\
\hline Maruotti et al. (24) & Retrospective & - & 219 & 553 & - & - & - & - \\
\hline Khalil et al. (22) & $\begin{array}{c}\text { Part of prospective } \\
\text { ongoing trial }\end{array}$ & - & 2278 & 28860 & $32.1 / 35.8$ & $48.9 \% / 35.2 \%$ & $24.2 / 24.4$ & $8.2 \% / 8.8 \%$ \\
\hline Odibo et al. (25) & Retrospective & - & 5232 & 4136 & $31.6 / 37.8$ & $33.1 \% / 26.2 \%$ & - & $8.7 \% / 9.8 \%$ \\
\hline Grobman et al. (21) & Retrospective & 501 & 152 & 653 & $35.9 / 37.4$ & $41.4 \% / 38.8 \%$ & $29.5 / 29.2$ & $1.6 \% / 1.3 \%$ \\
\hline Adusumalli et al. (19) & Retrospective & - & 1540 & 840 & $33.6 / 38.6$ & - & $25.5 / 29.3$ & - \\
\hline
\end{tabular}

Table 3. Outcomes according to the type of hypertensive pregnancy disorder

\begin{tabular}{|c|c|c|c|c|c|c|c|c|c|c|c|c|}
\hline & PRE & & & SPRE & & & GH & & & MAPHT & & \\
\hline Study/Year & CVS & AMNIO & Control & CVS & AMNIO & Control & CVS & AMNIO & Control & CVS & AMNIO & Control \\
\hline Sotiriadis et al. (26) & $14 / 437$ & - & $37 / 2969$ & - & - & - & - & - & - & - & - & - \\
\hline Daskalakis et al. (20) & $78 / 3165$ & $53 / 6822$ & - & - & - & - & $44 / 3199$ & $62 / 6813$ & - & $122 / 3121$ & $115 / 6760$ & - \\
\hline Maruotti et al. (24) & $5 / 219$ & - & $48 / 553$ & - & - & - & - & - & - & - & - & - \\
\hline Lindgren et al. (23) & - & - & - & - & - & - & - & - & - & 98/1984 & $955 / 21748$ & $2106 / 47854$ \\
\hline Khalil et al. (22) & $43 / 2278$ & - & $654 / 28860$ & - & - & - & $62 / 2278$ & & $795 / 28860$ & $105 / 2278$ & - & $1449 / 28860$ \\
\hline Odibo et al. (25) & $83 / 5096$ & - & $203 / 4002$ & $8 / 5096$ & - & $45 / 4002$ & $55 / 5096$ & - & $80 / 4002$ & $138 / 5096$ & - & $283 / 4002$ \\
\hline Grobman et al. (21) & $5 / 152$ & $12 / 501$ & $8 / 653$ & - & - & - & - & - & - & - & - & - \\
\hline Adusumalli et al. (19) & $56 / 1540$ & - & $33 / 840$ & $28 / 1540$ & - & $9 / 840$ & $7 / 1540$ & - & $4 / 840$ & $76 / 1540$ & - & $37 / 840$ \\
\hline Silver et al. (8) & - & - & - & $32 / 1878$ & $13 / 1820$ & - & - & - & - & $102 / 1878$ & $64 / 1820$ & - \\
\hline
\end{tabular}

\section{Statistical analysis}

Heterogeneity among the included studies was assessed using the $\mathrm{I}^{2}$ statistic. Thresholds for the interpretation of the $\mathrm{I}^{2}$ statistic were adapted from the Cochrane Handbook for Systematic Reviews of Interventions $(12,13)$. A guide to the interpretation of the $\mathrm{I}^{2}$ statistic is provided in Table 4 (12). The DerSimonian-Laird random-effects model was applied in the statistical analyses that were performed in this meta-analysis. We used RevMan ${ }^{\circledR}$ version 5 (The Cochrane Collaboration; Copenhagen: The Nordic Cochrane Centre, Copenhagen, Denmark) for the calculation of effect sizes and the corresponding 95\% confidence intervals (14). The results of scoring according to the customized checklist that was used to assess the methodological quality of the included studies are presented in Table 5. We used Cohen's kappa to determine the reliability of the checklist scores between the two reviewers. Values of Cohen's kappa were calculated using IBM SPSS ${ }^{\circledR}$ version 21 (IBM Corp.; Armonk, New York, USA) (15). We used the classification suggested by Landis and Koch for the interpretation of the values of Cohen's kappa (Table 6) (16). The prevalence rates of preeclampsia and merged acute pregnancyinduced hypertensive disorders among the pooling groups were compared using the Chi-square test with post hoc testing. For post hoc testing, we used adjusted standardized residuals and calculated p-values, which were evaluated for significance testing using the Bonferroni correction $(17,18)$.

\section{Results}

Our search of PubMed yielded nine studies that were eligible for consideration $(8,19-26)$. All of the identified studies were used in pooling and calculation of effect sizes, where appropriate, according to the pregnancy complication (Figure 1, Table 3). Midtrimester diagnostic amniocentesis was performed in four of the included studies, which were used as a control group for comparison where applicable $(8,20,21,23)$. We performed pooling into three subgroups according to the control group 
used for comparison: A) Patients with no invasive prenatal diagnostic procedure whatsoever (no invasive) (first pooling group); B) Patients with no invasive prenatal diagnostic procedure (no invasive) combined with patients who underwent midtrimester diagnostic amniocentesis (second pooling group); and C) Only patients who underwent midtrimester diagnostic amniocentesis (third pooling group).

Table 4. Ranges for the interpretation of the I2 statistic according to the Cochrane Handbook for Systematic Reviews of Interventions

\begin{tabular}{|l|l|}
\hline I2 statistic & Interpretation \\
\hline $0 \%-40 \%$ & might not be important \\
\hline $30 \%-60 \%$ & may represent moderate heterogeneity \\
\hline $50 \%-90 \%$ & may represent substantial heterogeneity \\
\hline $75 \%-100 \%$ & considerable heterogeneity \\
\hline
\end{tabular}

Table 5. Scores of the studies for methodological quality and respective values of Cohen's kappa

\begin{tabular}{|l|c|c|c|}
\hline Study/year & Reviewer \#1 & Reviewer \#2 & Kappa value \\
\hline Sotiriadis et al. (26) & 19 & 17 & 0.752 \\
\hline Daskalakis et al. (20) & 15 & 15 & 0.794 \\
\hline Maruotti et al. (24) & 4 & 4 & 0.623 \\
\hline Lindgren et al. (23) & 9 & 11 & 0.802 \\
\hline Khalil et al. (22) & 15 & 15 & 1 \\
\hline Odibo et al. (25) & 17 & 18 & 0.897 \\
\hline Grobman et al. (21) & 16 & 15 & 0.893 \\
\hline Adusumalli et al. (19) & 18 & 17 & 0.897 \\
\hline Silver et al. (8) & 16 & 16 & 0.775 \\
\hline
\end{tabular}

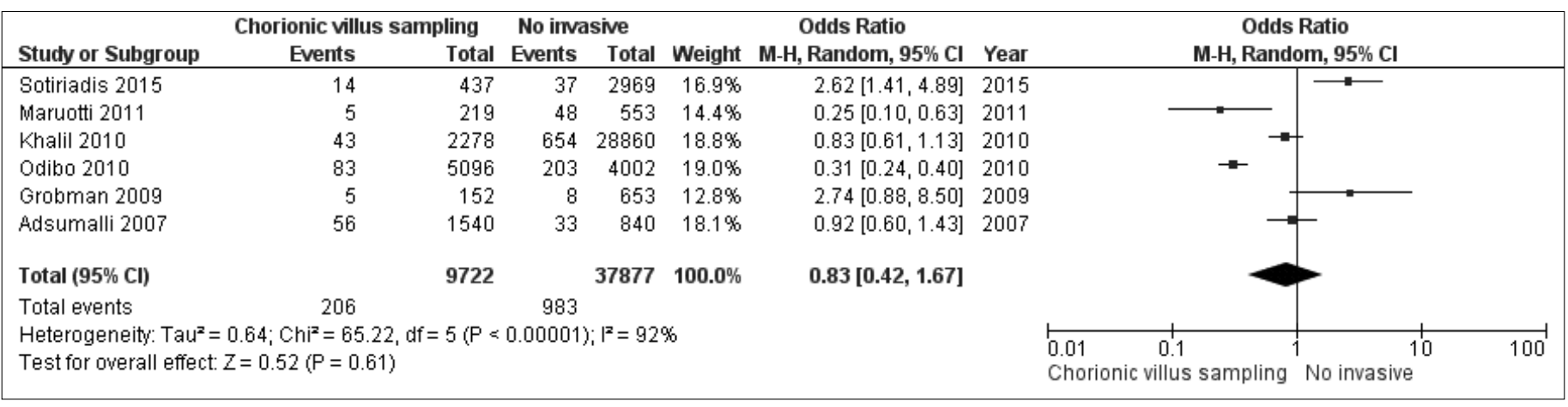

Figure 2. Forest plot of odds ratios for preeclampsia in the first pooling group

\begin{tabular}{|c|c|c|c|c|c|c|c|c|c|c|}
\hline \multirow[b]{2}{*}{ Study or Subgroup } & \multicolumn{2}{|c|}{ Chorionic villus sampling } & \multicolumn{2}{|c|}{ No imvasive } & \multicolumn{3}{|c|}{ Odds Ratio } & \multirow{2}{*}{\multicolumn{3}{|c|}{$\begin{array}{c}\text { Odds Ratio } \\
\text { M-H, Random, } 95 \% \mathrm{Cl}\end{array}$}} \\
\hline & \multirow{2}{*}{$\begin{array}{r}\text { Events } \\
8\end{array}$} & \multirow{2}{*}{$\begin{array}{l}\text { Total } \\
5096\end{array}$} & \multirow{2}{*}{ Events } & \multirow{2}{*}{$\begin{array}{l}\text { Total } \\
4002\end{array}$} & \multirow{2}{*}{$\begin{array}{r}\text { Weight } \\
50.0 \%\end{array}$} & \multirow{2}{*}{$\begin{array}{r}\text { M-H, Random, 95\% Cl } \\
0.14[0.07,0.29]\end{array}$} & \multirow{2}{*}{$\frac{\text { Year }}{2010}$} & & & \\
\hline Odibo 2010 & & & & & & & & - & & \\
\hline Adsumalli 2007 & 28 & 1540 & 9 & 840 & $50.0 \%$ & $1.71[0.80,3.64]$ & 2007 & & & \\
\hline Total $(95 \% \mathrm{Cl})$ & & 6636 & & 4842 & $100.0 \%$ & $0.49[0.04,5.78]$ & & & & \\
\hline Total events & 36 & & 54 & & & & & & & \\
\hline $\begin{array}{l}\text { Heterogeneity: Tau }{ }^{2} \\
\text { Test for overall effec }\end{array}$ & $\begin{array}{l}3.04 ; \mathrm{Chi}^{2}=21 \\
Z=0.57(P=0 .\end{array}$ & $=1(\mathrm{P} \leq$ & $0.00001)$ & $; 1^{2}=9$ & & & & $\begin{array}{ll}0.01 & 0.1 \\
\text { Chorionic villus }\end{array}$ & $v^{10}$ & 100 \\
\hline
\end{tabular}

Figure 3. Forest plot of odds ratios for severe preeclampsia in the first pooling group

\section{First pooling group}

The prevalence rates of preeclampsia were $2.12 \%(206 / 9,722)$ in the CVS patient group and $2.59 \%(983 / 37,877)$ in the control group. The $\mathrm{I}^{2}$ statistic was $92 \%$. No significant difference was found in the OR for preeclampsia between the CVS and control groups $(0.83,95 \%$ CI $0.42-1.67)$ (Figure 2 ).

The prevalence rates of severe preeclampsia were $0.54 \%$ $(36 / 6,636)$ in the CVS patient group and $1.12 \%(54 / 4,842)$ in the control group. The $\mathrm{I}^{2}$ statistic was $95 \%$. No significant difference was found in the OR for severe preeclampsia between the CVS and control groups $(0.49,95 \% \mathrm{CI} 0.04-5.78)$ (Figure 3$)$.

The prevalence rate of gestational hypertension was $1.39 \%$ $(124 / 8,914)$ in the CVS patient group and $2.61 \%(879 / 33,702)$ in the control group. The $\mathrm{I}^{2}$ statistic was $74 \%$. No significant difference was found in the OR for gestational hypertension between the CVS and control groups (0.76, 95\% CI 0.46-1.26) (Figure 4). The combination of all patients with preeclampsia or gestational hypertension led to prevalence rates of $3.83 \%(417 / 10,898)$ in the CVS patient group and $4.75 \%(3,875 / 81,556)$ in the control group. The $\mathrm{I}^{2}$ statistic was $96 \%$. No significant difference was found in the OR for preeclampsia and gestational hypertension

Table 6. Classification of Landis and Koch for values of Cohen's kappa

\begin{tabular}{|l|l|}
\hline Kappa value & Interpretation \\
\hline$<0.00$ & Poor \\
\hline $0.00-0.20$ & Slight \\
\hline $0.21-0.40$ & Fair \\
\hline $0.41-0.60$ & Moderate \\
\hline $0.61-0.80$ & Substantial \\
\hline $0.81-1.00$ & Almost perfect \\
\hline
\end{tabular}


combined between the CVS and control groups $(0.80,95 \% \mathrm{CI}$ 0.46-1.41) (Figure 5).

\section{Second pooling group}

The prevalence rates of preeclampsia were $2.2 \%(284 / 12,887)$ in the CVS patient group and $2.32 \%(1,048 / 45,200)$ in the pooled control group. The $\mathrm{I}^{2}$ statistic was $96 \%$. No significant difference was found in the OR for preeclampsia between the CVS and combined control groups (1.0, 95\% CI 0.46-2.18) (Figure 6).

A diagnosis of severe preeclampsia occurred in $0.80 \%(68 / 8,514)$ of the CVS patient group and $1.01 \%(67 / 6,662)$ of the study subjects in the combined control groups. The $\mathrm{I}^{2}$ statistic was $94 \%$. No significant difference was found in the OR for severe preeclampsia between the CVS and combined control groups (0.83, 95\% CI 0.14-4.85) (Figure 7).

Either preeclampsia or gestational hypertension was diagnosed in $4.06 \%(641 / 15,897)$ of the CVS patient group and $4.66 \%$ $(5,009 / 111,884)$ of the combined control group. The I ${ }^{2}$ statistic was $96 \%$. No significant difference was found in the OR for combined acute pregnancy-induced hypertensive disorders between the CVS and combined control groups (1.07, 95\% CI 0.63-1.84) (Figure 8).

\section{Third pooling group}

In two of the nine studies that were aggregated for this metaanalysis (20,21), patients who underwent midtrimester diagnostic amniocentesis but not CVS were utilized as a control group to assess any potential relationship with preeclampsia. The prevalence rates of preeclampsia were $2.5 \%(83 / 3,317)$ in the CVS patient group and $0.89 \%(65 / 7,323)$ in the midtrimester diagnostic amniocentesis patient group. The $\mathrm{I}^{2}$ statistic was $55 \%$. A significant difference was observed in the OR for preeclampsia between the CVS patient group and the midtrimester diagnostic amniocentesis patient group (2.47, 95\% CI 1.14-5.33) (Figure 9). Moreover, in three of the included studies $(8,20,23)$, data were available to evaluate merged acute pregnancy-induced hypertensive disorders in patients who only underwent midtrimester diagnostic amniocentesis. The prevalence rates of merged acute pregnancy-induced hypertensive disorders were 4.61\% $(322 / 6,983)$ in the CVS patient group and $3.74 \%(1,134 / 30,328)$ in the midtrimester diagnostic amniocentesis patient group. The $\mathrm{I}^{2}$ statistic was $89 \%$. A marginal difference was observed in the OR for merged acute pregnancy-induced hypertensive disorders between the CVS and midtrimester diagnostic amniocentesis patient groups (1.61, 95\% CI 1.02-2.53) (Figure 10).

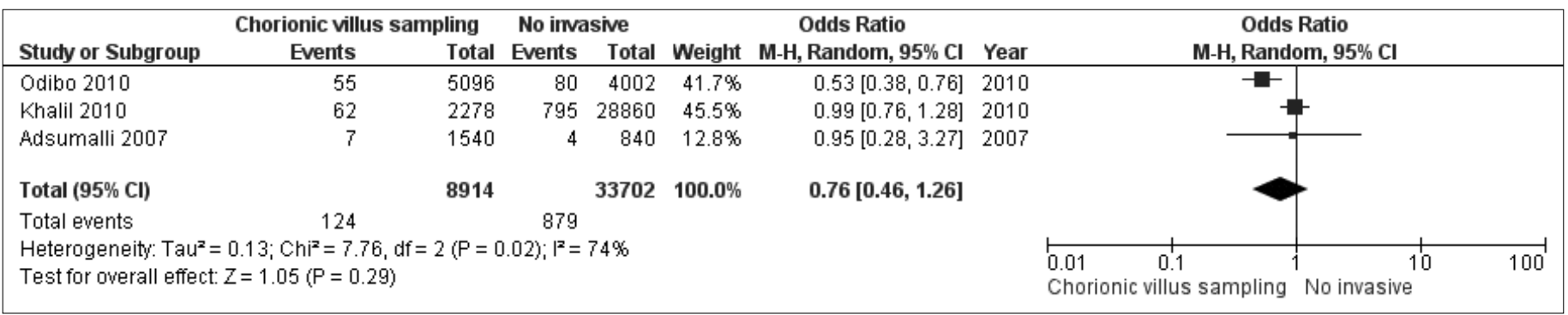

Figure 4. Forest plot of odds ratios for gestational hypertension in the first pooling group

\begin{tabular}{|c|c|c|c|c|c|c|c|c|c|}
\hline \multirow[b]{2}{*}{ Study or Subgroup } & \multicolumn{2}{|c|}{ Chorionic villus sampling } & \multicolumn{2}{|c|}{ No imvasive } & \multicolumn{3}{|c|}{ Odds Ratio } & \multirow{2}{*}{\multicolumn{2}{|c|}{$\begin{array}{c}\text { Odds Ratio } \\
\text { M-H, Random, } 95 \% \mathrm{Cl} \\
\end{array}$}} \\
\hline & Events & Total & Events & Total & Weight & M-H, Random, 95\% Cl & Year & & \\
\hline Lindgren 2010 & 98 & 1984 & 2106 & 47854 & $25.5 \%$ & $1.13[0.92,1.39]$ & 2010 & & \\
\hline Khalil 2010 & 105 & 2278 & 1449 & 28860 & $25.6 \%$ & $0.91[0.75,1.12]$ & 2010 & & \\
\hline Odibo 2010 & 138 & 5096 & 283 & 4002 & $25.5 \%$ & $0.37[0.30,0.45]$ & 2010 & 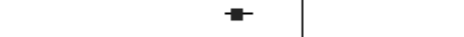 & \\
\hline Adsumalli 2007 & 76 & 1540 & 37 & 840 & $23.3 \%$ & $1.13[0.75,1.68]$ & 2007 & & \\
\hline Total $(95 \% \mathrm{Cl})$ & & 10898 & & 81556 & $100.0 \%$ & $0.80[0.46,1.41]$ & & & \\
\hline Total events & 417 & & 3875 & & & & & & \\
\hline $\begin{array}{l}\text { Heterogeneity: Tau } \\
\text { Test for overall effec }\end{array}$ & $\begin{array}{l}0.31 ; \mathrm{Chi}^{2}=68 \\
Z=0.77(P=0\end{array}$ & $=3(P \leq$ & 0.00001 & $i^{2}=96$ & & & & $\begin{array}{lll}0.01 & 0.1 & 1 \\
\text { Chorionic villus sampling } & \text { No invasive }\end{array}$ & 100 \\
\hline
\end{tabular}

Figure 5. Forest plot of odds ratios for all pregnancy-induced hypertensive disorders in the first pooling group

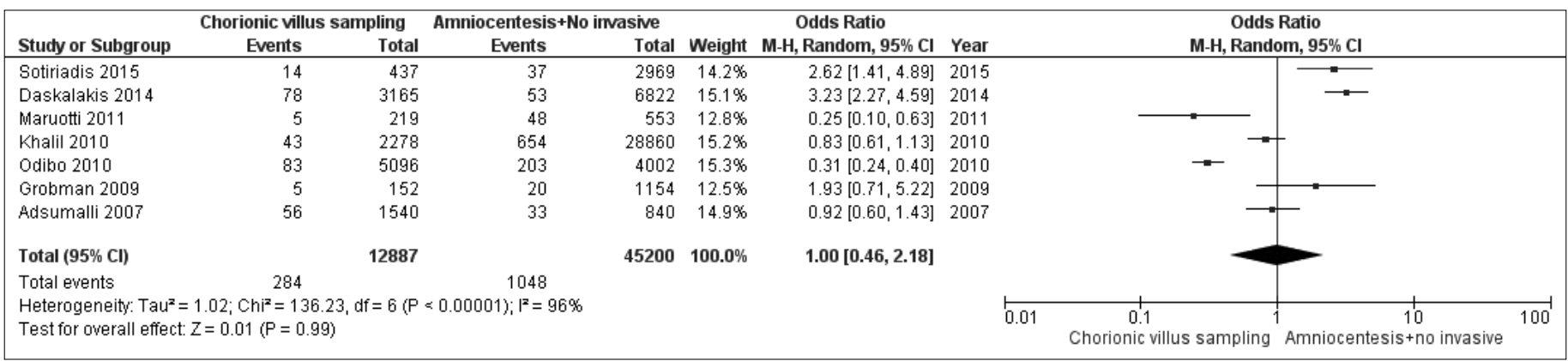

Figure 6. Forest plot of odds ratios for preeclampsia in the second pooling group 


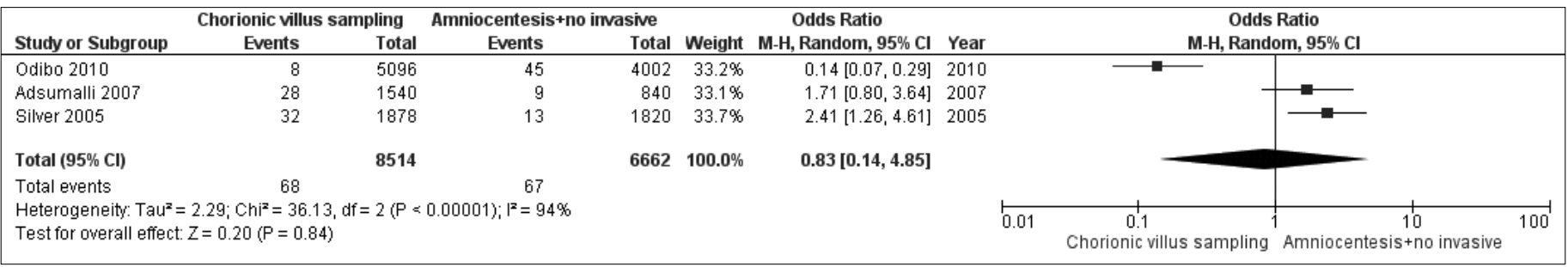

Figure 7. Forest plot of odds ratios for severe preeclampsia in the second pooling group

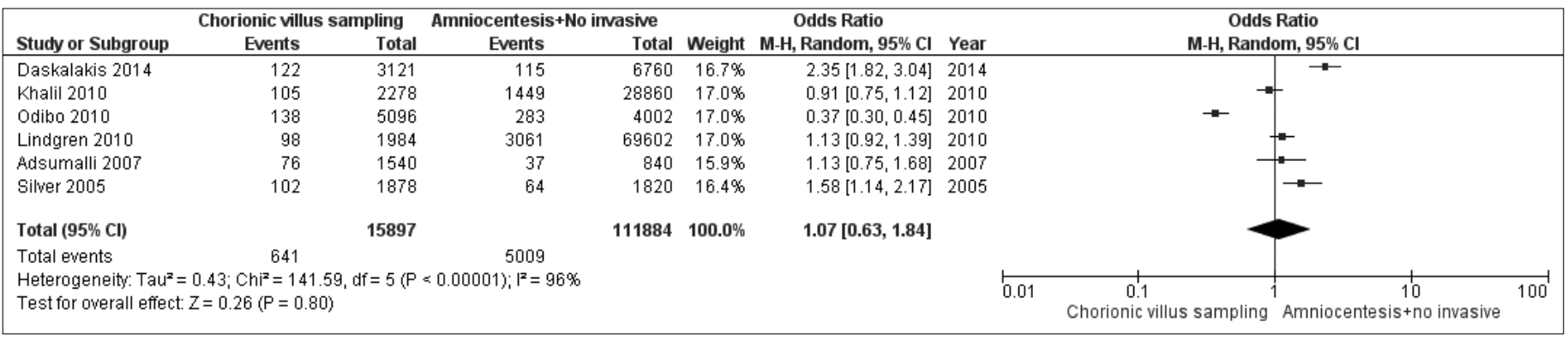

Figure 8. Forest plot of odds ratios for all pregnancy-induced hypertensive disorders in the second pooling group

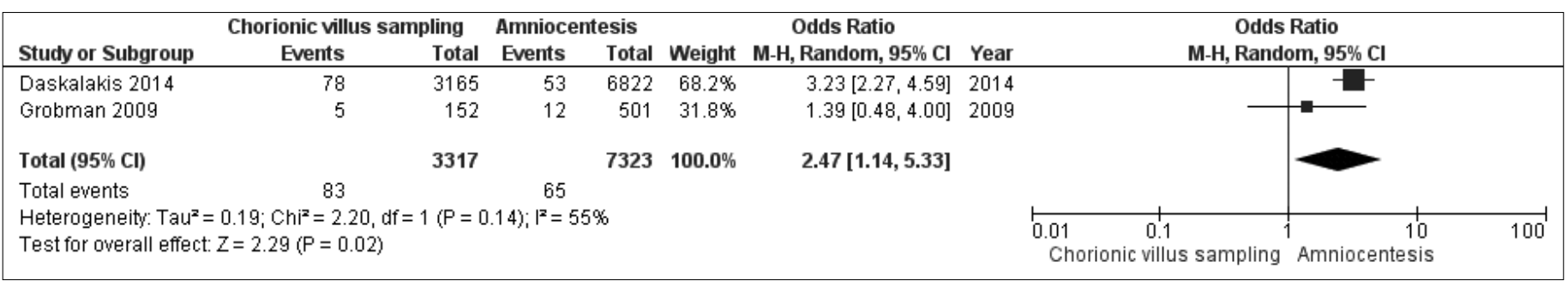

Figure 9. Forest plot of odds ratios for preeclampsia in the third pooling group

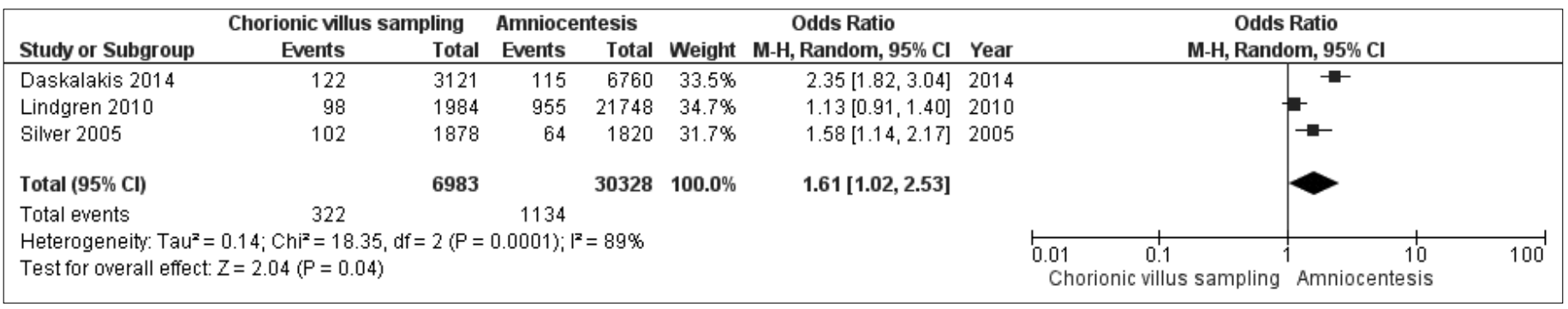

Figure 10. Forest plot of odds ratios for all pregnancy-induced hypertensive disorders in the third pooling group

\section{Discussion}

Among the studies that were included in the present metaanalysis, that by Silver et al. (8) constituted the stimulus for the subsequent research efforts. Two of the nine reports that met the criteria for this meta-analysis suggested that the risk for preeclampsia was reduced after a CVS procedure $(24,25)$. On the other hand, three reports suggested that the risk for preeclampsia was increased after a CVS procedure $(8,20,26)$. No significant effect of CVS on the risk of subsequent preeclampsia in either way was reported in the other four reports that were identified for our analysis (19, 21-23). Considerable heterogeneity was noted during pooling of the studies. The observed values of the $\mathrm{I}^{2}$ statistic during our analysis ranged between $55 \%$ and $96 \%$.
For our analysis of the data from the collected nine studies (8, 19-26), we created three pools of patients, as indicated previously. In the first two pooling groups, we did not find evidence of an increased risk for preeclampsia, severe preeclampsia, or gestational hypertension following the performance of first trimester CVS. However, in the last pooling group, the risk of preeclampsia appeared to increase following CVS (Figures 9 and 10).

The prevalence rates of preeclampsia were between $1.6 \%$ and $3.6 \%$ and between $0.8 \%$ and $8.6 \%$ in the CVS and control groups, respectively, in the studies that were evaluated for this analysis. Most of the individually reported rates were considerably lower than the typically reported prevalence of preeclampsia of $5 \%-8 \%$ (2). Nevertheless, a recent prospective randomized study, which included only nulliparous women, reported an occurrence of 
preeclampsia of approximately 7\% (27). It is notable that the rates of nulliparity varied between $15.3 \%$ and $48.9 \%$ among the nine reports, with the largest study having a considerably lower rate of nulliparity in comparison with the other studies (Table 2). Therefore, the relatively low prevalence of preeclampsia among the pooled studies may in part be due to the low nulliparity rate and the retrospective structure of the included studies.

To investigate the sources of the differences between the three pooling groups, we constructed tables for the assessment of prevalence. In Tables 7 and 8, the rates of preeclampsia and merged acute pregnancy-induced hypertensive disorders according to the three pooling groups are provided. Firstly, the rates of preeclampsia were similar among the CVS arms of the three pooling groups $(p=0.447)$ (Table 7$)$. Secondly, Chisquare testing indicated a marginal difference for merged acute pregnancy-induced hypertensive disorders $(p=0.042)$, which lost its significance after post hoc testing among the CVS arms of the three pooling groups (Table 8). However, the rates of preeclampsia and merged acute pregnancy-induced hypertensive disorders among the control arms of the three pooling groups were significantly different from each other $(p<0.001)$ (Table 7 , 8 ). Post hoc testing indicated that the rates were significantly lower in the control arm of the third pooling group $(\mathrm{p}<0.001)$. The significantly lower rates of preeclampsia and merged acute pregnancy-induced hypertensive disorders in the control arm of the third pooling group mostly originated from the study of Daskalakis et al. (20). In this study, it is notable that $83.1 \%$ of the study subjects underwent CVS for an indication of thalassemia, and the nulliparity rate was significantly higher in the CVS group

Table 7. Prevalence of preeclampsia according to the three pooling groups

\begin{tabular}{|l|c|c|}
\hline Pooling group & $\begin{array}{c}\text { Chorionic villus } \\
\text { sampling group }\end{array}$ & Control group \\
\hline A & $2.12 \%$ & $2.59 \%$ \\
\hline B & $2.2 \%$ & $2.32 \%$ \\
\hline C & $2.5 \%$ & $0.89 \%$ \\
\hline $\begin{array}{l}\text { A: patients with no invasive procedures served as the control group } \\
\text { (first pooling group); B: patients with no invasive procedures combined }\end{array}$ \\
$\begin{array}{l}\text { with patients who underwent midtrimester diagnostic amniocentesis } \\
\text { served as the control group (second pooling group); C: patients who } \\
\text { underwent midtrimester diagnostic amniocentesis but not chorionic } \\
\text { villus sampling (CVS) served as the control group (third pooling group) }\end{array}$ \\
\hline
\end{tabular}

Table 8. Prevalence of merged acute pregnancy-induced hypertensive disorders according to three pooling groups

\begin{tabular}{|l|c|c|}
\hline Pooling group & $\begin{array}{c}\text { Chorionic villus } \\
\text { sampling group }\end{array}$ & Control group \\
\hline A & $3.83 \%$ & $4.75 \%$ \\
\hline B & $4.06 \%$ & $4.66 \%$ \\
\hline C & $4.61 \%$ & $3.74 \%$ \\
\hline
\end{tabular}

A: patients with no invasive procedures served as the control group (first pooling group); B: patients with no invasive procedures combined with patients who underwent midtrimester diagnostic amniocentesis served as the control group (second pooling group); C: patients who underwent midtrimester diagnostic amniocentesis but not chorionic villus sampling (CVS) served as the control group (third pooling group)
(20). Daskalakis et al. (20) emphasized that anemia secondary to thalassemia is a protective factor against preeclampsia (28). Hence, they concluded that despite the purported protective effect of undergoing CVS in a thalassemic patient, CVS actually increased the risk for preeclampsia. In contrast, Hangrasertpong et al. (29) reported outcomes for thalassemia traits recently and debated the pros and cons of a purported protective effect of thalassemia against preeclampsia. Their data revealed a marginally higher risk of preeclampsia in patients that carried a thalassemia trait [OR 1.73 (95\% CI 1.01-3.00)] (29). Another important weakness of the conclusions of Daskalakis et al. (20) was the performance of multiple regression analysis that excluded information regarding nulliparity and anemia. To strengthen their conclusions, nulliparity and the presence of anemia should have been included in the regression analysis. Similarly, Sotiriadis et al. (26) reported increased rates of preeclampsia after CVS [3.2\% vs. 1.6\%; OR 2.62 (95\% CI 1.41-4.89)], but after controlling for confounding factors in their logistic regression analysis, the performance of CVS lost its effect. Thus, the results shown for the third pooling group are weakened and are likely due to a sampling error. Interpreted in this context, the data in Tables 7 and 8 suggest that midtrimester diagnostic amniocentesis has either no effect or perhaps an ironic protective effect in reducing the occurrence of preeclampsia. Figures 6 and 8 incorporate most of the available data and provide the best summary result, which indicates that CVS has no effect on the occurrence of preeclampsia.

The grading scores of the investigations chosen for inclusion in this meta-analysis according to the checklist are shown in Table 5. The two investigations reported by Lindgren et al. (23) and Maruotti et al. (24) are conspicuous by the fact that their scores were low compared with the others. This finding was not expected, particularly for the Lindgren report given the large number of included subjects. The two reviewers indicated average scores for the other included studies. The scores that are indicated in Table 5 reflect the moderate methodology and reporting quality of the studies in this analysis.

It is important to note the limitations of the current metaanalysis. To begin with, none of the studies in this analysis were structured as a randomized prospective clinical trial designed to study the effect of CVS on the subsequent occurrence of preeclampsia. On the other hand, portions of two trials had some prospective components $(8,22)$. The report of Silver et al. (8) was a secondary analysis of a randomized trial, which was underpowered owing to difficulties in obtaining the necessary sample size (30). In addition, the report of Khalil et al. (22) indicated that their trial was part of an ongoing prospective study, but actually the outcomes were acquired retrospectively. Therefore, the trials of Khalil et al. and Silver et al. were analyzed with other trials. Amongst the studies included in this meta-analysis, only Adusumalli et al. (19) performed a power analysis. They calculated that 1471 patients were necessary in each arm to achieve sufficient statistical power to avoid the trial being underpowered. In the current meta-analysis, we observed considerable heterogeneity. As a result of the significant heterogeneity observed among the results, the power of this meta-analysis is limited (31). 
In summary, the aggregated available information suggests that CVS does not have a significant adverse impact on future pregnancy outcomes with regard to the occurrence of acute hypertensive disease in the form of either gestational hypertension or preeclampsia. We acknowledge that our review is limited by considerable heterogeneity and the retrospective design of the available studies, which are prone to sampling error. Prospective randomized clinical trials are clearly required to determine with confidence if first trimester CVS performed via either the transvaginal or transabdominal route has a significant adverse impact upon the later development of pregnancy-specific hypertension.

\section{Ethics Committee Approval: N/A}

\section{Informed Consent: $N / A$}

Peer-review: Externally peer-reviewed.

Author Contributions: Concept - A.B.; Design - A.B., M.B., B.T., J.N.M.Jr.; Supervision - A.B., M.B., B.T., J.N.M.Jr.; Materials - A.B., M.B., B.T., J.N.M.Jr.; Data Collection and/or Processing - A.B., M.B., B.T., J.N.M.Jr.; Analysis and/or Interpretation - A.B., M.B., B.T., J.N.M.Jr.; Literature Review - A.B., M.B., B.T., J.N.M.Jr.; Writer - A.B., M.B., B.T., J.N.M.Jr.; Critical Review A.B., M.B., B.T., J.N.M.Jr.; Other - A.B., M.B., B.T., J.N.M.Jr.

Conflict of Interest: No conflict of interest was declared by the authors.

Financial Disclosure: The authors declared that this study has received no financial support.

\section{References}

1. Duley L. Maternal mortality associated with hypertensive disorders of pregnancy in Africa, Asia, Latin America and the Caribbean. Br J Obstet Gynaecol 1992; 99: 547-53. [CrossRef]

2. Gupta S, Agarwal A, Sharma RK. The role of placental oxidative stress and lipid peroxidation in preeclampsia. Obstet Gynecol Surv 2005; 60: 807-16. [CrossRef]

3. Redman CW. Preeclampsia: a multi-stress disorder. Rev Med Interne 2011; 32(Suppl 1): S41-4. [CrossRef]

4. Carty DM, Delles C, Dominiczak AF. Preeclampsia and future maternal health. J Hypertens 2010; 28: 1349-55. [CrossRef]

5. Lyall F. Mechanisms regulating cytotrophoblast invasion in normal pregnancy and pre-eclampsia. Aust N Z J Obstet Gynaecol 2006; 46: 266-73. [CrossRef]

6. Farina A, Hasegawa J, Raffaelli S, Ceccarini C, Rapacchia G, Pittalis $\mathrm{MC}$, et al. The association between preeclampsia and placental disruption induced by chorionic villous sampling. Prenat Diagn 2010; 30: 571-4. [CrossRef]

7. Katiyar R, Kriplani A, Agarwal N, Bhatla N, Kabra M. Detection of fetomaternal hemorrhage following chorionic villus sampling by Kleihauer Betke test and rise in maternal serum alpha feto protein. Prenat Diagn 2007; 27: 139-42. [CrossRef]

8. Silver RK, Wilson RD, Philip J, Thom EA, Zachary JM, Mohide P, et al. Late first-trimester placental disruption and subsequent gestational hypertension/preeclampsia. Obstet Gynecol 2005; 105: 587-92. [CrossRef]

9. Basaran A, Basaran M, Topatan B. Chorionic villus sampling and the risk of preeclampsia: a systematic review and meta-analysis. Arch Gynecol Obstet 2011; 283: 1175-81. [CrossRef]

10. Stroup DF, Berlin JA, Morton SC, Olkin I, Williamson GD, Rennie $\mathrm{D}$, et al. Meta-analysis of observational studies in epidemiology: a proposal for reporting. Meta-analysis Of Observational Studies in Epidemiology (MOOSE) group. JAMA 2000; 283: 2008-12. [CrossRef]

11. Rangel SJ, Kelsey J, Colby CE, Anderson J, Moss RL. Development of a quality assessment scale for retrospective clinical studies in pediatric surgery. J Pediatr Surg 2003; 38: 390-6: discussion 390-6.
12. Higgins JPT, Green S, (editors). Cochrane Handbook for Systematic Reviews of Interventions. The Cochrane Colloboration. 2011; Version 5.1.0 [updated March 2011] (http://handbook.cochrane. org/front_page.htm).

13. Rucker G, Schwarzer G, Carpenter JR, Schumacher M. Undue reliance on I(2) in assessing heterogeneity may mislead. BMC Med Res Methodol 2008; 8: 79. [CrossRef]

14. Review Manager (RevMan) [Computer program]. Version 5.0. Copenhagen: The Nordic Cochrane Centre, The Cochrane Collaboration, 2008. Epub Version 5.0.

15. IBM SPSS statistics for Windows [Computer program]. Version 21. 21 ed. Armonk, NY: IBM Corp; 2012.

16. Landis JR, Koch GG. The measurement of observer agreement for categorical data. Biometrics 1977; 33: 159-74. [CrossRef]

17. Beasley TM, Schumacker RE. Multiple regression approach to analyzing contingency tables: Post hoc and planned comparison procedures. J Exp Educ 1995; 64: 79-93. [CrossRef]

18. García-pérez MA, Núñez-antón V. Cellwise residual analysis in two-way contingency tables. Educ Psychol Meas 2003; 63: 825-39. [CrossRef]

19. Adusumalli J, Han CS, Beckham S, Bartholomew ML, Williams J 3rd. Chorionic villus sampling and risk for hypertensive disorders of pregnancy. Am J Obstet Gynecol 2007; 196: 591 e1-7; discussion e7.

20. Daskalakis G, Papapanagiotou A, Antonakopoulos N, Mesogitis S, Papantoniou N, Loutradis D, et al. Invasive diagnostic procedures and risk of hypertensive disorders in pregnancy. Int $\mathrm{J}$ Gynaecol Obstet 2014; 125: 146-9. [CrossRef]

21. Grobman WA, Auger M, Shulman LP, Elias S. The association between chorionic villus sampling and preeclampsia. Prenat Diagn 2009; 29: 800-3. [CrossRef]

22. Khalil A, Akolekar R, Pandya P, Syngelaki A, Nicolaides K. Chorionic villus sampling at 11 to 13 weeks of gestation and hypertensive disorders in pregnancy. Obstet Gynecol 2010; 116: 374-80. [CrossRef]

23. Lindgren P, Cederholm M, Haglund B, Axelsson O. Invasive procedures for fetal karyotyping: no cause of subsequent gestational hypertension or pre-eclampsia. BJOG 2010; 117: 1422-5. [CrossRef]

24. Maruotti GM, Agangi A, Martinelli P. Chorionic villus sampling and the thalassemia trait: which relationship with pre-eclampsia? BJOG 2011; 118: 764-5. [CrossRef]

25. Odibo AO, Singla A, Gray DL, Dicke JM, Oberle B, Crane J. Is chorionic villus sampling associated with hypertensive disorders of pregnancy? Prenat Diagn 2010; 30: 9-13.

26. Sotiriadis A, Eleftheriades M, Chatzinikolaou F, Chatzistamatiou K, Assimakopoulos E, Chasiakos D. Fetal growth impairment after first-trimester chorionic villus sampling: a case-control study. J Matern Fetal Neonatal Med 2016; 29: 1731-5.

27. Roberts JM, Myatt L, Spong CY, Thom EA, Hauth JC, Leveno KJ, et al. Vitamins $\mathrm{C}$ and $\mathrm{E}$ to prevent complications of pregnancy-associated hypertension. N Engl J Med 2010; 362: 1282-91. [CrossRef]

28. Murphy JF, O'Riordan J, Newcombe RG, Coles EC, Pearson JF. Relation of haemoglobin levels in first and second trimesters to outcome of pregnancy. Lancet 1986; 1: 992-5. [CrossRef]

29. Hanprasertpong T, Kor-anantakul O, Leetanaporn R, Suntharasaj T, Suwanrath C, Pruksanusak N, et al. Pregnancy outcomes amongst thalassemia traits. Arch Gynecol Obstet 2013; 288: 1051-4. [CrossRef]

30. Philip J, Silver RK, Wilson RD, Thom EA, Zachary JM, Mohide P, et al. Late first-trimester invasive prenatal diagnosis: results of an international randomized trial. Obstet Gynecol 2004; 103: 1164-73. [CrossRef]

31. Borenstein M, Hedges LV, Higgins JPT, Rothstein HR. Power Analysis for Meta-Analysis. Borenstein M, Hedges LV, Higgins JPT, Rothstein HR, editors. Introduction to Meta-Analysis. Chichester, UK: John Wiley \& Sons; 2009. [CrossRef] 